\title{
Significance of mitochondrial calcium and nitric oxide for apoptosis of human breast cancer cells induced by tamoxifen and etoposide
}

\author{
ARTI PARIHAR, MORDHWAJ S. PARIHAR and PEDRAM GHAFOURIFAR \\ Department of Surgery, Davis Heart and Lung Research Institute, and Institute of Mitochondrial Biology, \\ The Ohio State University, Columbus, OH 43210, USA
}

Received September 13, 2007; Accepted October 22, 2007

\begin{abstract}
In the present study, we tested the significance of mitochondria for apoptosis upon exposure to tamoxifen and etoposide using two human breast cancer cell lines, MCF-7 and MDA-MB-231. We showed that both tamoxifen and etoposide induced apoptosis, increased intramitochondrial calcium and nitric oxide, and decreased mitochondrial transmembrane potential in both cell lines. Both drugs increased mitochondrial protein tyrosine nitration and caused release of cytochrome $\mathrm{c}$ from the mitochondria of both cell lines. This study suggests that tamoxifen and etoposide utilize a common mechanism to induce apoptosis in MCF-7 and MDA-MB-231 cells.
\end{abstract}

\section{Introduction}

Breast cancer, the second most common cause of death in women, is caused in part by insufficient apoptosis (1). Cancer cells are resistant to apoptosis, and inadequate apoptosis promotes both the initial phase of carcinogenesis and the development of chemotherapy resistance. Mitochondria play a crucial role in apoptosis (2-5). During apoptosis, mitochondria produce high levels of reactive oxygen and nitrogen species, the mitochondrial transmembrane potential $(\Delta \psi)$ declines, and mitochondrial intermembrane protein cytochrome $\mathrm{c}$ is released. Many cancer chemotherapeutic agents induce apoptosis via a mechanism involving mitochondria, nitric oxide (NO), and peroxynitrite. For example, tamoxifen (TAM) which induces apoptosis via mitochondria-dependent pathways $(6,7)$ increases peroxynitrite in isolated mitochondria (8). Etoposide (ETP), a widely used drug of a different drug

Correspondence to: Dr Pedram Ghafourifar, The Ohio State University, 460 West 12th Avenue, Columbus, OH 43210, USA

E-mail: pedram.ghafourifar@osumc.edu

Key words: mitochondrial calcium, nitric oxide, apoptosis, breast cancer, tamoxifen, etoposide family, has also been shown to induce apoptosis by inducing cytochrome $\mathrm{c}$ release in isolated mitochondria and by causing cell death via mitochondria-dependent pathways (9). It has also been suggested that ETP increases mitochondrial calcium, releases cytochrome c from mitochondria and induces apoptosis in Jurkat cells (10). Staurosporine is another chemotherapeutic agent that induces apoptosis in human breast cancer cells $(11,12)$. In PC12 cells, staurosporineinduced apoptosis is mediated by elevated $\mathrm{Ca}^{2+}$ and increased oxidative stress, and is prevented by peroxynitrite scavengers (13). Doxorubicin, another cancer chemotherapeutic agent, induces apoptosis via increased oxidative stress and decreased $\Delta \psi(14,15)$.

Intramitochondrial calcium $\left[\mathrm{Ca}^{2+}\right]_{\mathrm{m}}$ is critical for apoptosis $(16,17)$. Elevated $\left[\mathrm{Ca}^{2+}\right]_{\mathrm{m}}$ induces apoptosis in various cells $(13,18,19)$. This form of apoptosis requires increased NO synthase (NOS) activity $(18,19)$ and is prevented by lowering mitochondrial superoxide $(4,20)$ or by scavenging peroxynitrite (13). Mitochondrial NOS produces NO in response to elevated $\left[\mathrm{Ca}^{2+}\right]_{\mathrm{m}}(21,22)$. A considerable portion of mitochondrial NO reacts with superoxide and forms peroxynitrite $(22,23)$ that releases cytochrome $\mathrm{c}$ from the mitochondria and induces mitochondrial apoptosis $(8,23,24)$. The interplay between $\left[\mathrm{Ca}^{2+}\right]_{\mathrm{m}}$, mitochondrial $\mathrm{NO}$, and mitochondrial peroxynitrite for apoptosis of many cells including brain, heart and kidney has been studied (22). However, the significance of $\left[\mathrm{Ca}^{2+}\right]_{\mathrm{m}}$, mitochondrial $\mathrm{NO}$, and peroxynitrite for human breast cancer cells is not well known. We recently showed that in isolated mitochondria TAM increases $\left[\mathrm{Ca}^{2+}\right]_{\mathrm{m}}$ which stimulates mitochondrial NOS, elevates mitochondrial peroxynitrite, and causes mitochondrial apoptosis (8), and we hypothesized that $\left[\mathrm{Ca}^{2+}\right]_{\mathrm{m}}$, mitochondrial NO and peroxynitrite may play key roles in apoptosis of breast cancer cells. In the present study the mechanism of apoptosis in MCF-7 and MDA-MB-231 cells induced by two drugs of different families was tested. We showed that both TAM and ETP increased $\left[\mathrm{Ca}^{2+}\right]_{\mathrm{m}}$ and mitochondrial $\mathrm{NO}$, caused a decrease in $\Delta \psi$, increased mitochondrial protein tyrosine nitration, caused cytochrome c release and induced apoptosis in MCF-7 and MDA-MB-231 cells. Our findings suggest that TAM and ETP utilize a common mechanism to induce apoptosis in human breast cancer cells. 

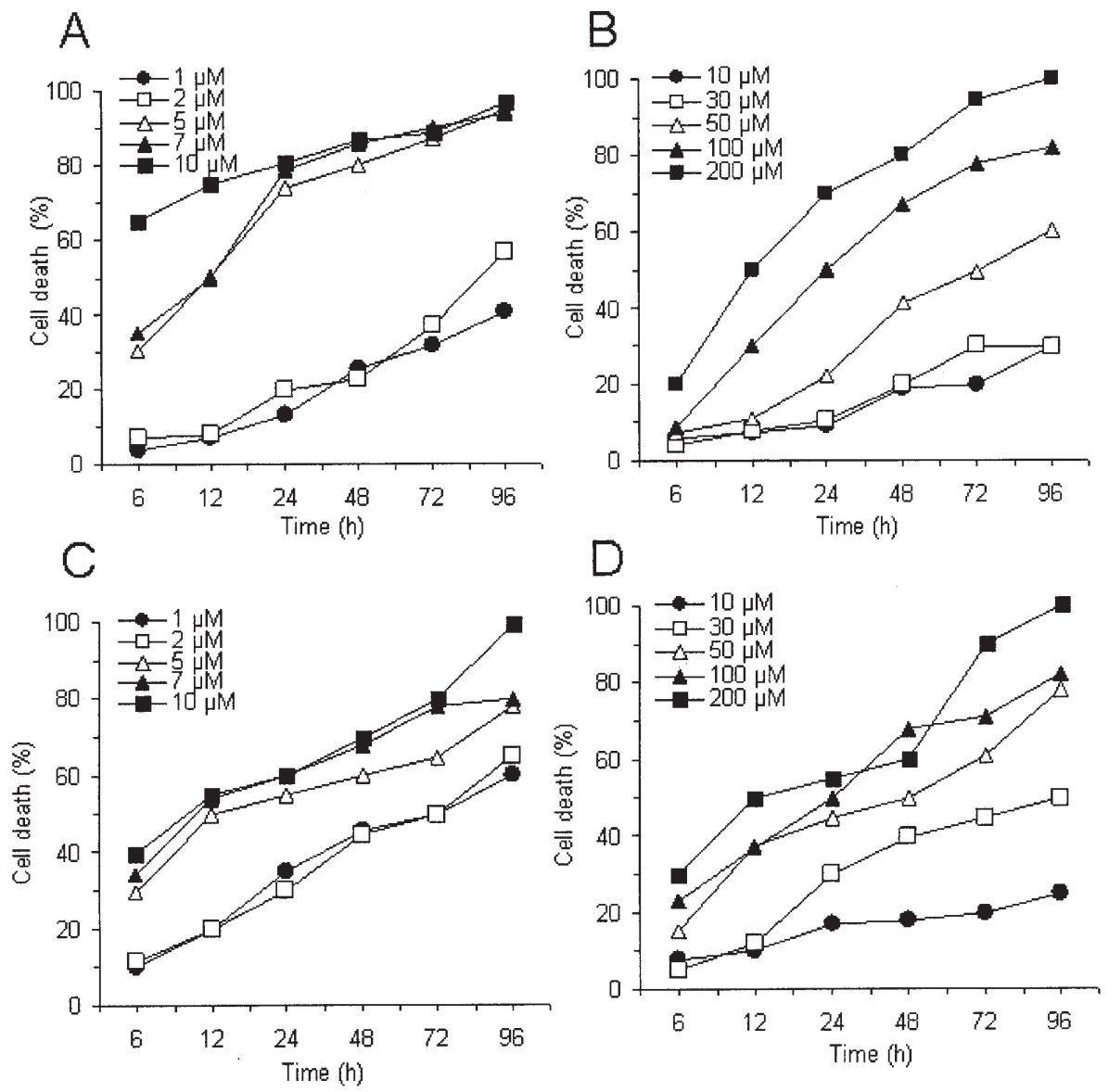

Figure 1. Dose- and time-response. (A) MCF-7 cells treated with varying doses of tamoxifen (TAM) showing $\mathrm{LC}_{50}$ of $5 \mu \mathrm{M}$ after $12 \mathrm{~h}$ of treatment. (B) MCF-7 cells treated with varying doses of etoposide (ETP) showing $\mathrm{LC}_{50}$ of $200 \mu \mathrm{M}$ after $12 \mathrm{~h}$. (C) MDA-MB-231 cells treated with TAM showing LC ${ }_{50}$ after $12 \mathrm{~h}$ of treatment at $5 \mu \mathrm{M}$. (D) MDA-MB-231 cells treated with ETP showing $\mathrm{LC}_{50}$ of $200 \mu \mathrm{M}$ after $12 \mathrm{~h}$.

\section{Materials and methods}

Materials. Dulbecco's modified Eagle's medium (DMEM), fetal bovine serum (FBS), rhodamine-2, AM (Rhod-2), tetramethylrhodamine methyl ester (TMRM), Hoechst 33342, mitotracker red, mitotracker green, and Alexa Fluor 488 were purchased from Invitrogen. 4,5-Diaminofluorescein diacetate (DAF) was purchased from Calbiochem. Monoclonal anti-nitrotyrosine antibody was purchased from Alexis. Monoclonal anti-cytochrome c antibody was purchased from eBioscience. Vectashield was purchased from Vector Laboratories. All other chemicals were purchased from Sigma.

Cell culture. MCF-7 and MDA-MB-231, two human breast cancer cell lines, were purchased from ATCC (Manassas, VA) and maintained in DMEM supplemented with FBS $(10 \%)$, L-glutamine $(2 \mathrm{mM})$, penicillin $(100 \mathrm{IU} / \mathrm{ml})$, and streptomycin $(100 \mu \mathrm{g} / \mathrm{ml})$ in a humidified incubator with $5 \%$ $\mathrm{CO}_{2}$ and $95 \%$ air at $37^{\circ} \mathrm{C}$. Cells were seeded at a density of $5 \times 10^{5} / \mathrm{ml}$ in 24 -well plates on 12 -mm glass coverslips.

Treatments. For apoptosis induction, cells were cultured in DMEM containing FBS (5\%). Cells were treated with TAM (1-10 $\mu \mathrm{M})$ or ETP $(10-200 \mu \mathrm{M})$ for $96 \mathrm{~h}$. Control cells were treated with the same amount of vehicle.
Hoechst staining assay. Chromatin condensation was detected by staining with Hoechst 33342. Cells were grown on glass coverslips as described above. At $80 \%$ confluence, cells were treated with TAM and ETP. These cells were incubated with chromatin-specific Hoechst $33342(3 \mu \mathrm{g} / \mathrm{ml})$ for $30 \mathrm{~min}$ to distinguish non-apoptotic cells from cells with apoptotic nuclear morphology (25). The fluorescent images of the control, TAM- and ETP-treated cells were captured at $750 \mathrm{~nm}$ by a Zeiss confocal laser scanning microscope (LSM 510) equipped with a multiphoton laser using a x20 objective. Cells with apoptotic nuclear morphology were scored.

Intramitochondrial calcium. $\left[\mathrm{Ca}^{2+}\right]_{\mathrm{m}}$ was measured by loading cells with Rhod-2 (5 $\mu \mathrm{M})$ (26) and simultaneously with mitotracker green $(200 \mathrm{nM})$. Initially, cells were loaded with Rhod-2 in DMEM and incubated at room temperature for 15 min followed by the addition of mitotracker green and further incubation for an additional 30 min under $5 \% \mathrm{CO}_{2}$ at $37^{\circ} \mathrm{C}$. After loading with Rhod-2 and mitotracker green, cells were permeabilized with digitonin $(10 \mu \mathrm{M})$ and washed with calcium-free Hank's balanced salt solution to eliminate the cytosolic fraction of Rhod-2 (27).

Mitochondrial nitric oxide. Mitochondrial NO was measured by using a membrane-permeable fluorescent probe DAF 
A
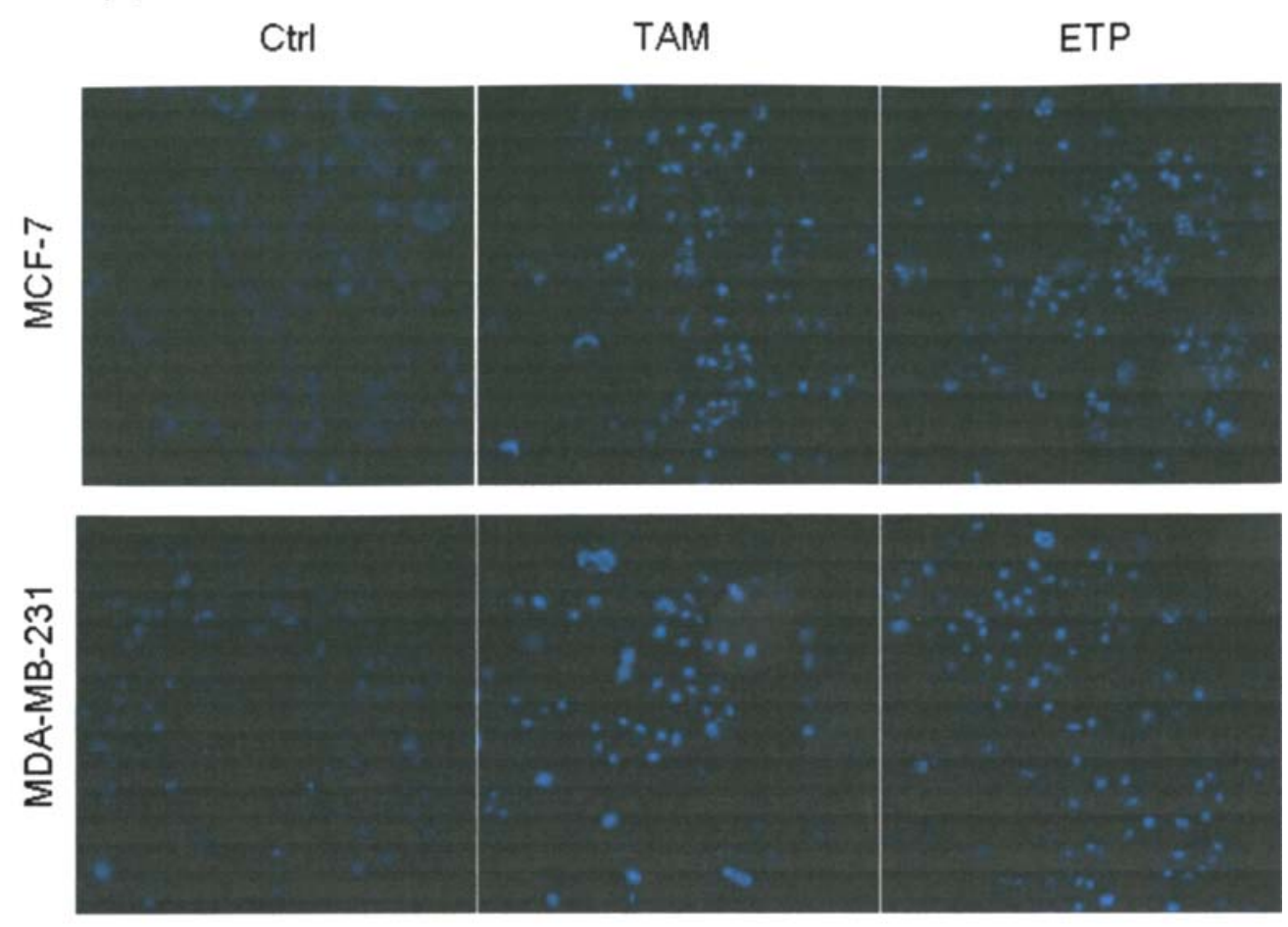

B

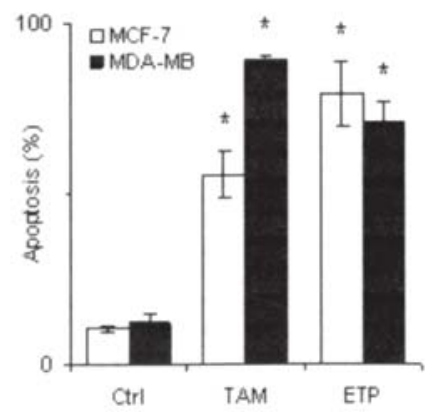

$(5 \mu \mathrm{M})$ (28). Initially, cells were incubated with mitotracker red $(200 \mathrm{nM})$ for 5 min followed by incubation with DAF for an additional $15 \mathrm{~min}$ in DMEM under $5 \% \mathrm{CO}_{2}$ at $37^{\circ} \mathrm{C}$.

Mitochondrial transmembrane potential. The $\Delta \psi$ was measured by loading cells with TMRM (10 nM) and mitotracker green $(200 \mathrm{nM})$ in DMEM and by incubating in $5 \% \mathrm{CO}_{2}$ at $37^{\circ} \mathrm{C}$ for $20 \min (29)$.

Protein tyrosine nitration and cytochrome $c$ detection. Cells were labeled with mitotracker red $(500 \mathrm{nM})$ under $5 \% \mathrm{CO}_{2}$ at $37^{\circ} \mathrm{C}$ for $45 \mathrm{~min}$ and fixed in paraformaldehyde $(4 \%)$ for 15-20 min at room temperature. Cells were permeabilized with Triton X-100 (0.2\%) followed by blocking in goat serum (10\%). Cells were incubated with anti-nitrotyrosine primary antibody (1:250) or anti-cytochrome c primary antibody (1:200) overnight at $4{ }^{\circ} \mathrm{C}$, followed by incubation with Alexa Fluor 488 secondary antibody (1:200) for $1 \mathrm{~h}$ at room temperature and air dried. The cells were mounted with Vectashield on a glass slide.
Figure 2. Apoptosis. (A) Control (Ctrl)-, tamoxifen (TAM)- and etoposide (ETP)-treated MCF-7 and MDA-MB-231 cells showing chromatin condensation indicated by the highly fluorescent blue signals of Hoechst 33342. (B) The percentage of cells with apoptotic nuclei was determined. ${ }^{*} \mathrm{p}<0.05$ vs the control.
Fluorescent imaging. Coverslips containing live cells were washed twice with a low fluorescence medium and mounted in a microchamber. Acquisition of fluorescence was performed in DMEM without phenol red, and images were obtained using a Zeiss confocal laser scanning microscope (LSM 510) using a x63 water objective. Fluorescence imaging of live cells loaded with different fluorescent dyes or fixed immunostained cells was performed using multichannel detection of excitation with the $488 \mathrm{~nm}$ line of an argon laser and the 543 and 633 lines of Helium Neon 1 and Helium Neon 2 and the $750 \mathrm{~nm}$ line of multiphoton laser at room temperature. Fluorescence images of cells loaded with mitotracker red, TMRM and Rhod-2 were acquired using 543-nm excitation and $579-\mathrm{nm}$ emission. Fluorescence images of DAF, mitotracker green and Alexa Fluor 488 were acquired using 488- $\mathrm{nm}$ excitation and 516-nm emission. Images were acquired at 12-bit resolution by taking a single $\mathrm{z}$-stack $1-\mu \mathrm{m}$ steps. Fluorescence images were analyzed using ImageJ software (National Institute of Health). Barograms are the mean \pm SEM of 6 images. Differences were tested by the 
A
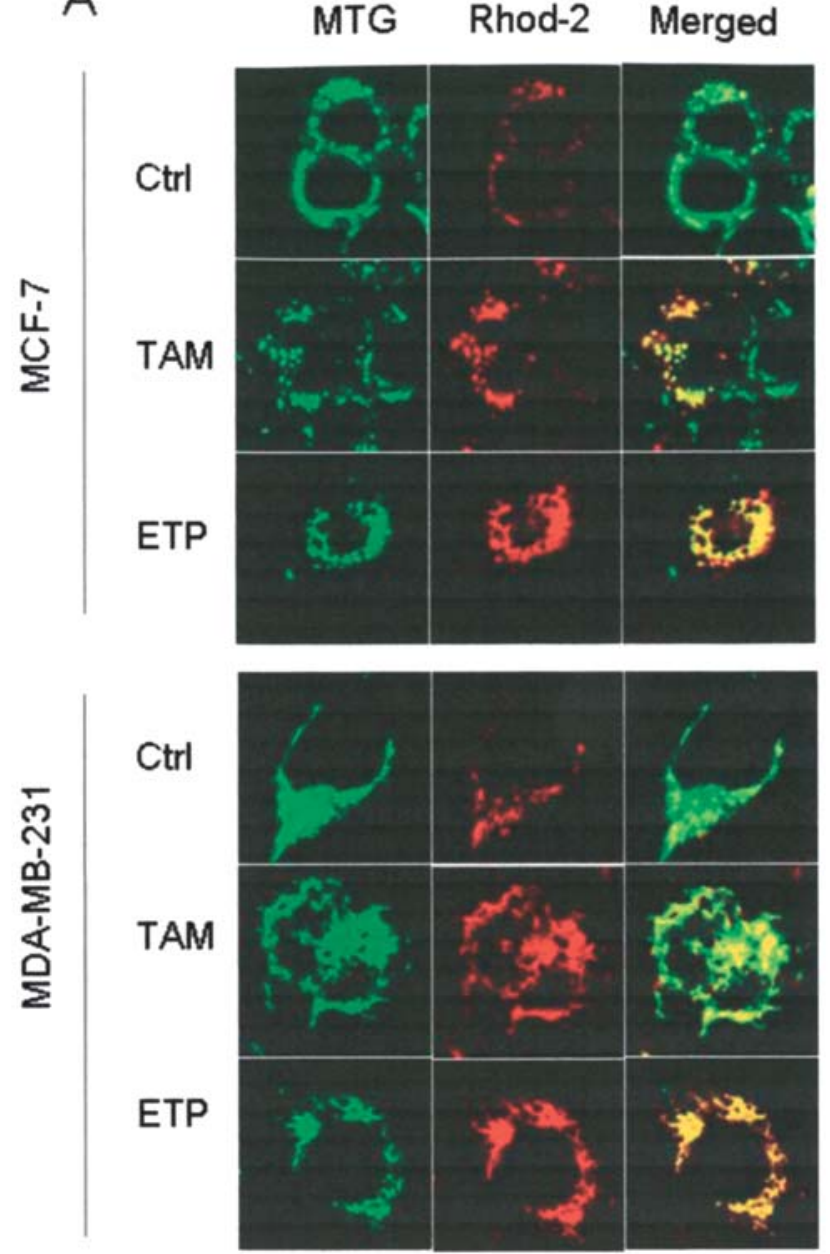

B

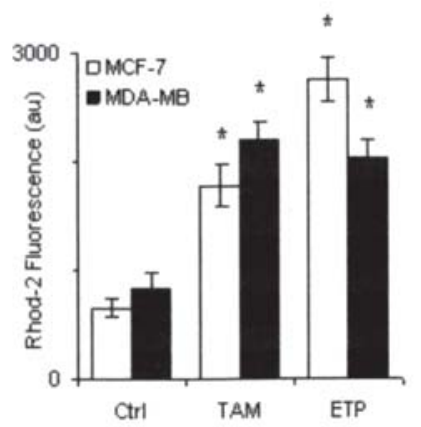

Figure 3. Intramitochondrial calcium $\left[\mathrm{Ca}^{2+}\right]_{\mathrm{m}}$. (A) Control (Ctrl)-, tamoxifen (TAM)- or etoposide (ETP)-treated MCF-7 and MDA-MB-231 cells. Images of mitotracker green (MTG), Rhod-2, AM (Rhod-2) and merged are shown. Merged images are overlaid images of MTG and Rhod-2. (B) $\left[\mathrm{Ca}^{2+}\right]_{\mathrm{m}}$ was measured after TAM or ETP treatment. " $\mathrm{p}<0.05$ vs the control.

Student's t-test and considered statistically significant at $\mathrm{p}<0.05$.

\section{Results}

Dose- and time-response. Fig. 1A-D shows dose- and timeresponse curves for both cell lines treated with TAM or ETP. $\mathrm{LC}_{50}$ at $12 \mathrm{~h}$ of treatment was found to be $5 \mu \mathrm{M}$ for TAM and $200 \mu \mathrm{M}$ for ETP for both cell lines.
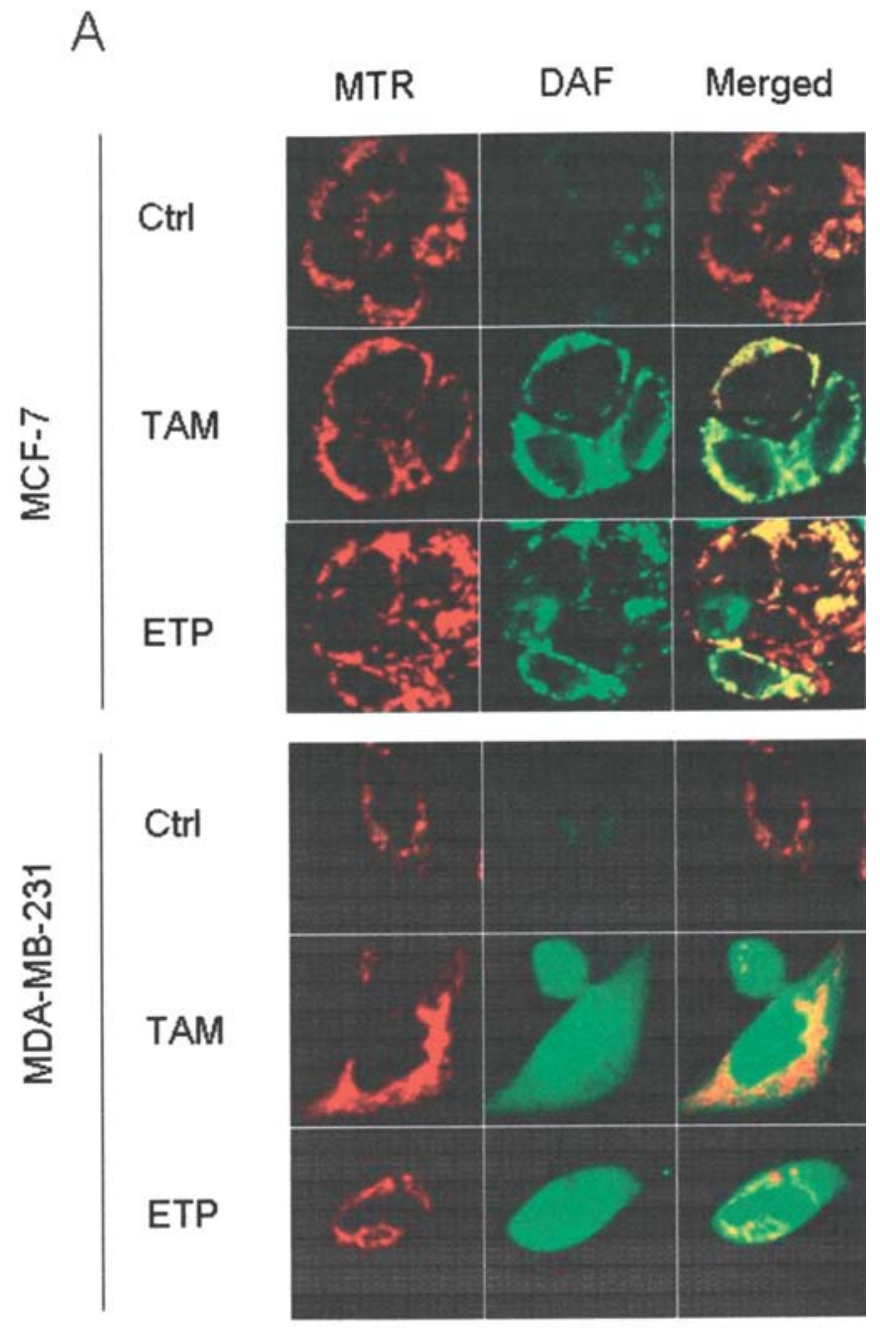

B

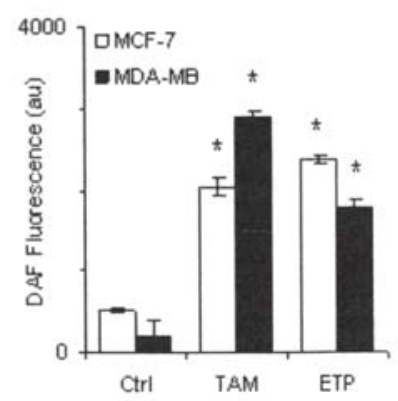

Figure 4. Intramitochondrial nitric oxide (NO). (A) Control (Ctrl)-, tamoxifen (TAM)- or etoposide (ETP)-treated MCF-7 and MDA-MB-231 cells. Images of mitotracker red (MTR), DAF-2DA (DAF) and merged are shown. Merged images are overlaid images of MTR and DAF. (B) NO was measured after TAM or ETP treatment. ${ }^{\mathrm{p}}<0.05$ vs the control.

TAM and ETP induce apoptosis. Fig. 2A shows Hoechst 33342 fluorescence in MCF-7 and MDA-MB-231 cells. Apoptosis indicated by condensed nuclei with the intense blue fluorescence of Hoechst 33342 was increased by TAM and ETP in MCF-7 and MDA-MB-231 cells. Fig. 2B shows the increase in the percentage of apoptotic cells by TAM and ETP treatments in those cell types.

TAM and ETP increase intramitochondrial calcium. Fig. 3A and B shows an increase in the Rhod-2 fluorescence signal 
A
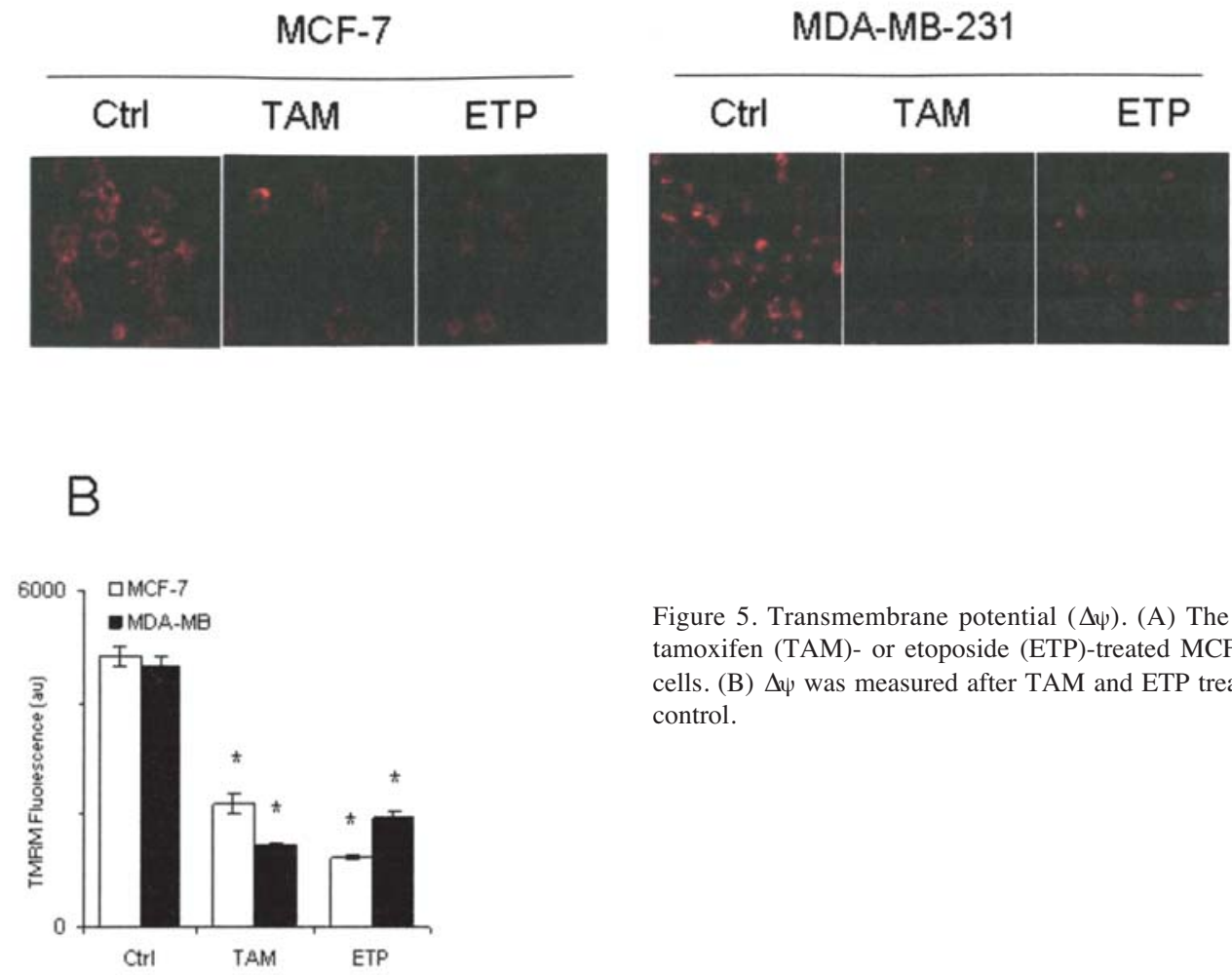

Figure 5. Transmembrane potential $(\Delta \psi)$. (A) The $\Delta \psi$ of control (Ctrl)-, tamoxifen (TAM)- or etoposide (ETP)-treated MCF-7 and MDA-MB-231 cells. (B) $\Delta \psi$ was measured after TAM and ETP treatments. " $\mathrm{p}<0.05$ vs the control.

after TAM and ETP treatments that co-localized within mitochondria in both cell types. These findings indicate that TAM and ETP increased $\left[\mathrm{Ca}^{2+}\right]_{\mathrm{m}}$ in both MCF-7 and MDAMB-231 cells. Barograms show the fluorescence intensity measurement of Rhod-2 indicating a significant increase in $\left[\mathrm{Ca}^{2+}\right]_{\mathrm{m}}$ in comparison to the control.

TAM and ETP increase mitochondrial nitric oxide. Fig. 4A and $\mathrm{B}$ shows the increase in the DAF signal in TAM- and ETP-treated MCF-7 and MDA-MB-231 cells that were colocalized with mitotracker red (yellow fluorescence in merged images). Barograms show the fluorescence intensity measurement of the DAF signal in both cell lines treated with TAM and ETP. As shown, the fluorescence intensity was significantly higher in the mitochondria of TAM- and ETPtreated cells compared to the control cells, indicating increased NO in the mitochondria.

TAM and ETP decrease mitochondrial transmembrane potential. Decrease in TMRM fluorescence indicated decreased $\Delta \psi$. Fig. 5A and B shows a decrease in $\Delta \psi$ in TAM- and ETP-treated MCF-7 and MDA-MB-231 cells. The bar diagram shows that the fluorescence intensity of the TMRM signal in MCF-7 and MDA-MB-231 cells treated with TAM and ETP were decreased indicating a decrease in $\Delta \psi$.

TAM and ETP increase mitochondrial protein tyrosine nitration and induce cytochrome c release. Fig. $6 \mathrm{~A}$ and $\mathrm{B}$ shows a dramatic increase in mitochondrial protein tyrosine nitration immunoreactivity in TAM- and ETP-treated cells. The bar diagram shows a significant increase in tyrosine

nitration immunofluorescence intensity indicating a significant increase in nitrated tyrosine after TAM and ETP treatments. Fig. 7 shows the immunofluorescence intensity of cytochrome $\mathrm{c}$ that is punctated and co-localized within the mitochondria of control cells indicating localization of cytochrome $\mathrm{c}$ in the mitochondria, whereas in TAM- and ETP-treated cells cytochrome c is scattered in the cytoplasm, indicating the release of cytochrome $\mathrm{c}$ from the mitochondria.

\section{Discussion}

The present study demonstrated that TAM and ETP induce apoptosis in both MCF-7 and MDA-MB-231 cells. Both drugs increased $\left[\mathrm{Ca}^{2+}\right]_{\mathrm{m}}$ and mitochondrial $\mathrm{NO}$, decreased $\Delta \psi$, increased mitochondrial protein tyrosine nitration, and caused cytochrome c release.

We first tested various concentrations of TAM and ETP to induce cell death in both cell lines. Fig. 1A-D shows the time course of various concentrations of TAM and ETP in both cells. As shown, $12 \mathrm{~h}$ of incubation of both cell lines with $5 \mu \mathrm{M}$ TAM or $200 \mu \mathrm{M}$ ETP caused $50 \%$ cell death. In order to confirm that the apoptotic cell death caused by TAM or ETP was apoptotic, the Hoechst assay was used. As shown in Fig. 1A-D, $5 \mu \mathrm{M}$ TAM or $200 \mu \mathrm{M}$ ETP caused apoptosis in both cell types. Therefore, these concentrations of TAM and ETP were used throughout the study.

Perturbed cellular $\mathrm{Ca}^{2+}$ homeostasis causes apoptosis (30-32). $\mathrm{Ca}^{2+}$-dependent mitochondrial dysfunction is a critical event that leads to the release of cytochrome $\mathrm{c}$ from mitochondria (33). Fig. 3A and B shows that TAM and ETP caused a significant increase in $\left[\mathrm{Ca}^{2+}\right]_{\mathrm{m}}$ in both types of human breast cancer cells. Mitochondria rapidly and efficiently store 
A
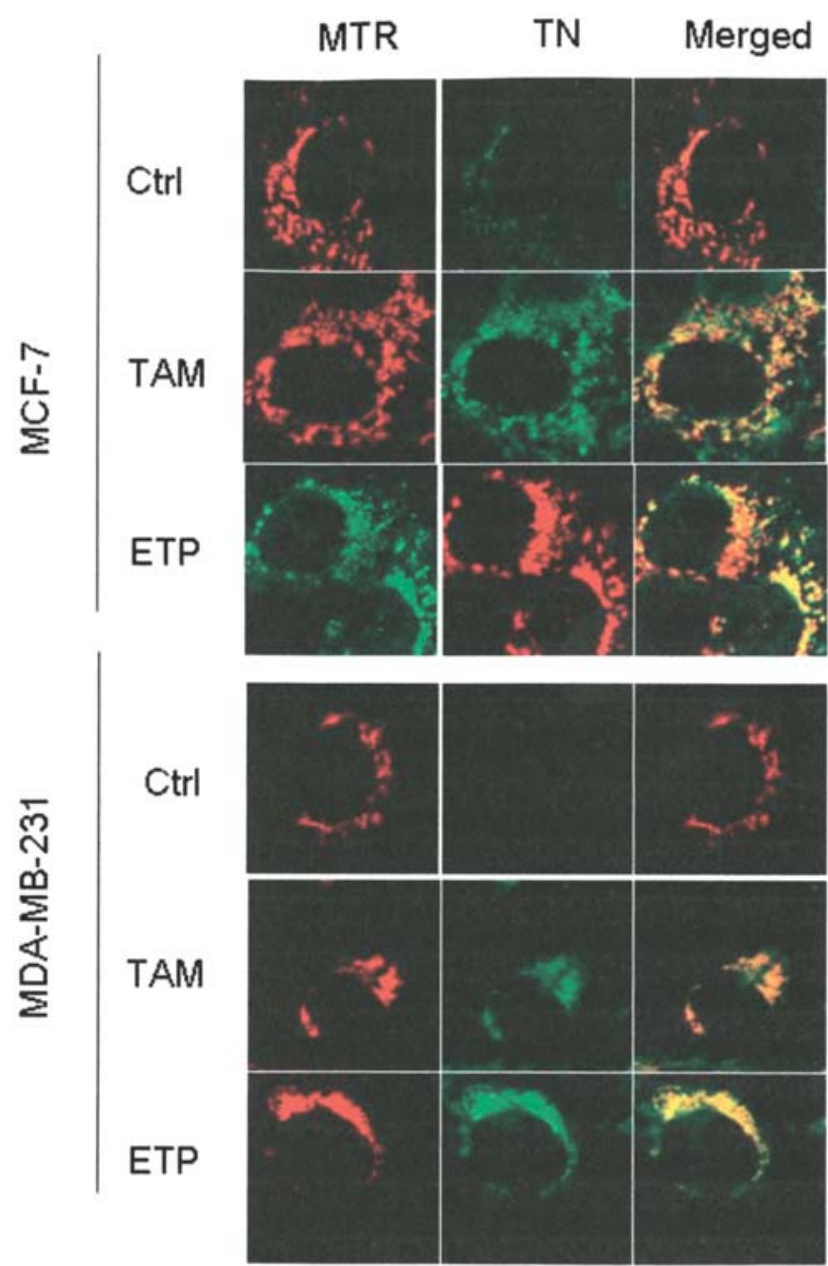

B

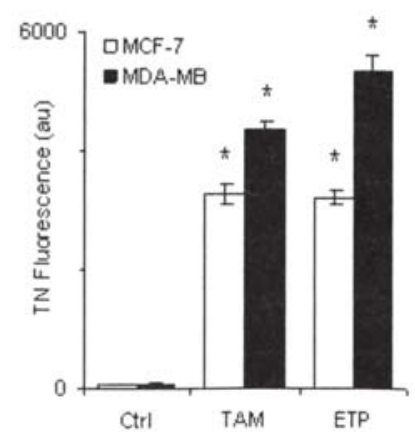

Figure 6. Protein tyrosine nitration (TN). (A) TN in the mitochondria of control (Ctrl)-, tamoxifen (TAM)- or etoposide (ETP)-treated MCF-7 and MDA-MB-231 cells. Merged images show the overlay of mitotracker red (MTR) with anti-nitrotyrosine antibody immunoreactivity (TN). Higher colocalization in the mitochondria shows higher TN in the mitochondria. (B) Quantification of protein tyrosine nitration in the mitochondria of control (Ctrl)-, tamoxifen (TAM)- and etoposide (ETP)-treated cells. ${ }^{*} \mathrm{p}<0.01$ vs the control.

large amounts of $\left[\mathrm{Ca}^{2+}\right]_{\mathrm{m}}$, however, mitochondria maintain very low $\left[\mathrm{Ca}^{2+}\right]_{\mathrm{m}}$ by precipitating $\left[\mathrm{Ca}^{2+}\right]_{\mathrm{m}}$ to matrix electrondense granules $(8,24,34-38)$. By precipitating and releasing $\left[\mathrm{Ca}^{2+}\right]_{\mathrm{m}}$ from these granules, mitochondria maintain dynamic intra-organelle calcium homeostasis $(8,24,39-42)$. Intramitochondrial calcium homeostasis can be altered by drugs,
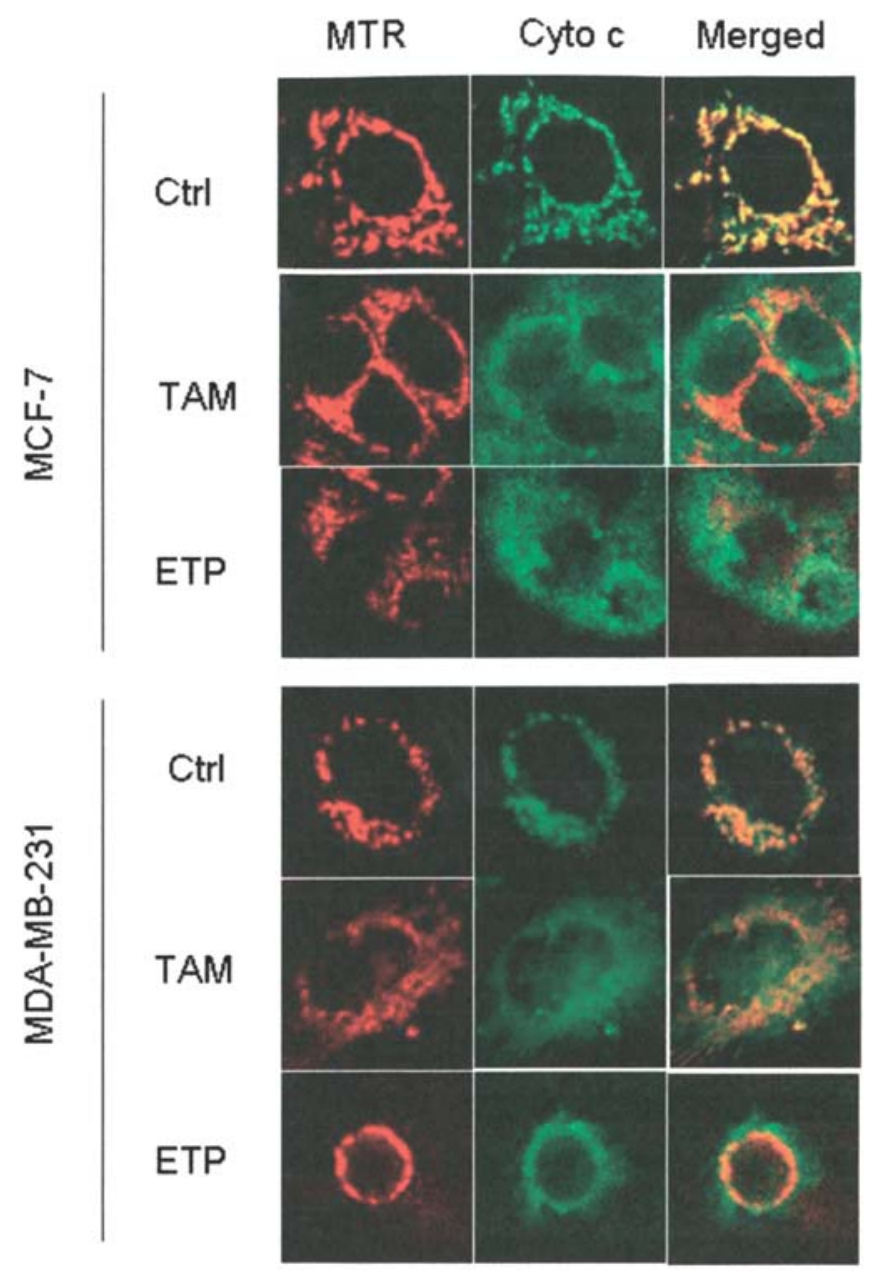

Figure 7. Cytochrome c (Cyto c) release. Cyto $\mathrm{c}$ in control (Ctrl)-, tamoxifen (TAM)- or etoposide (ETP)-treated MCF-7 and MDA-MB-231 cells. Merged images are of mitotracker red (MTR) with anti-cytochrome c reactivity (cyto c). Punctated cytochrome c signal in control cells shows localization of cyto $\mathrm{c}$ in the mitochondria. Diffused cyto c signal in TAMand ETP-treated cells shows cyto c release from mitochondria.

hormones, or pathologic conditions (34-36,39-44). For example, vasopressin has been shown to decrease the matrix calcium granules in the mitochondria of neurons (40), and hypoxia increases the matrix granules in heart mitochondria (44). Recently, we showed that reperfusion after hypoxia increases $\left[\mathrm{Ca}^{2+}\right]_{\mathrm{m}}$ in heart mitochondria stimulating mitochondrial NO formation (24). We showed that TAM increases $\left[\mathrm{Ca}^{2+}\right]_{\mathrm{m}}$ in isolated rat liver mitochondria and in mitochondria isolated from MCF-7 cells, and suggested that elevated $\left[\mathrm{Ca}^{2+}\right]_{\mathrm{m}}$ causes TAM-induced mitochondrial NOS stimulation (8). Fig. 3A and B shows that both drugs increased $\left[\mathrm{Ca}^{2+}\right]_{\mathrm{m}}$ in both human breast cancer cells. These findings are consistent with our recent report on isolated mitochondria (8), and we propose that the elevation of $\left[\mathrm{Ca}^{2+}\right]_{\mathrm{m}}$ could be considered a common response to TAM and ETP. Elevation of $\left[\mathrm{Ca}^{2+}\right]_{\mathrm{m}}$ stimulates mitochondrial NOS activity which increases mitochondrial NO $(8,23,24,45)$. Therefore, we tested mitochondrial NO upon treatment with TAM and ETP. As shown in Fig. 4A and B, TAM and ETP increased mitochondrial NO in both cell lines. Thus the present results confirm our previous findings on isolated mitochondria (8) 
and suggest that elevated mitochondrial NO might be involved in cell death caused by TAM and ETP.

NO decreases $\Delta \psi$ via inhibition of cytochrome c oxidase $(46,47)$. Decreased $\Delta \psi$ is an early event in apoptosis which is followed by release of cytochrome c (48). Apoptosis involving decreased $\Delta \psi$ and cytochrome c release has been demonstrated in MCF-7 cells after irradiation (49). As shown in Fig. 5A and B, TAM and ETP decreased $\Delta \psi$ in both cancer cell lines. Other reports have also shown a decrease in $\Delta \psi$ by anticancer chemotherapeutic drugs. For example, TAM decreased the $\Delta \psi$ in MCF-7 cells (50) and in isolated mitochondria (8). Thus, the findings illustrated in Fig. 5A and B suggest that the decrease in $\Delta \psi$ is associated with apoptosis induced by both TAM and ETP.

High levels of NO induce apoptosis in tumor cells via peroxynitrite formation (51). Peroxynitrite has a very short lifetime in most biological environments. Therefore, protein tyrosine nitration has been used as a peroxynitrite biomarker (8). Fig. 6A and B shows increased protein tyrosine nitration in cells treated with TAM and ETP. These data indicate that TAM and ETP treatment increased mitochondrial NO, leading to the generation of peroxynitrite. Previous findings indicate that the majority of tyrosine-nitrated protein in muscle cells are located in the mitochondria (52). The present study supports these reports and shows that upon treatment of cancer cells with TAM and ETP, a large amount of tyrosine nitration was found in the mitochondria suggesting that mitochondrial peroxynitrite might contribute to apoptosis induced by TAM and ETP.

Release of cytochrome $\mathrm{c}$ is a key event during apoptosis (2). Upon loss of $\Delta \psi$ and release of cytochrome c, most cells are committed to apoptosis (53). Changes in mitochondrial function induced by different apoptotic stimuli are associated with release of cytochrome c into the cytosol $(54,55)$. Peroxynitrite induces cytochrome c release by tyrosine nitration (56). Since TAM and ETP induced apoptosis (Fig. 2A and B) and caused elevation of mitochondrial peroxynitrite (Fig. 4A and B), we tested cytochrome c release in cells treated with TAM or ETP. Fig. 7 shows that in the control cells, cytochrome c co-localized within the mitochondria, whereas TAM- and ETP-treated cells showed diffused cytochrome $\mathrm{c}$ signals indicating redistribution of cytochrome c into the cytosol. Thus, apoptosis induced by TAM and ETP in both types of cells is associated with the release of cytochrome $\mathrm{c}$.

We also demonstrated that changes in mitochondrial functions are critically associated with cell death caused by treatment with both TAM and ETP by a common mechanism. TAM and ETP are prototypes of two drug families with different known mechanisms of actions. TAM and ETP induced apoptosis in two human breast cancer cell lines MCF-7 and MDA-MB-231 by a very similar mechanism consisting of increased $\left[\mathrm{Ca}^{2+}\right]_{\mathrm{m}}$ and mitochondrial $\mathrm{NO}$, decreased $\Delta \psi$, as well as increased mitochondrial peroxynitrite and cytochrome $\mathrm{c}$ release from mitochondria. Breast cancer is a multifactor disease and standardized treatments are not available for patients. An understanding of the mechanisms underlying cell death by TAM and ETP may be helpful in developing new therapeutic agents and in improving the selectivity of the treatment.

\section{References}

1. Sjostrom $\mathbf{J}$ and Bergh $\mathrm{J}$ : How apoptosis is regulated, and what goes wrong in cancer. BMJ 322: 1538-1539, 2001.

2. Green DR and Reed JC: Mitochondria and apoptosis. Science 281: 1309-1312, 1998.

3. Kroemer G: Mitochondrial control of apoptosis: an overview. Biochem Soc Symp 66: 1-15, 1999.

4. Ghafourifar P, Bringold U, Klein SD and Richter C: Mitochondrial nitric oxide synthase, oxidative stress and apoptosis. Biol Signals Recept 10: 57-65, 2001

5. Szibor M, Richter C and Ghafourifar P: Redox control of mitochondrial functions. Antioxid Redox Signal 3: 515-523, 2001

6. Grad JM, Cepero E and Boise LH: Mitochondria as targets for established and novel anti-cancer agents. Drug Resist Updat 4: 85-91, 2001.

7. Dietze EC, Caldwell LE, Grupin SL, Mancini M and Seewaldt VL: Tamoxifen but not 4-hydroxytamoxifen initiates apoptosis in p53(-) normal human mammary epithelial cells by inducing mitochondrial depolarization. J Biol Chem 276: 5384-5394, 2001

8. Nazarewicz RR, Zenebe WJ, Parihar A, Larson SK, Alidema E, Choi $\mathrm{J}$ and Ghafourifar P: Tamoxifen induces oxidative stress and mitochondrial apoptosis via stimulating mitochondrial nitric oxide synthase. Cancer Res 67: 1282-1290, 2007.

9. Park JH and Kim TH: Release of cytochrome c from isolated mitochondria by etoposide. J Biochem Mol Biol 38: 619-623, 2005.

10. Robertson JD, Gogvadze V, Zhivotovsky B and Orrenius S: Distinct pathway for stimulation of cytochrome c release by etoposide. J Biol Chem 275: 32438-32443, 2000.

11. Chen JS, Konopleva M, Andreeff M, Multani AS, Pathak S and Mehta K: Drug-resistant breast carcinoma (MCF-7) cells are paradoxically sensitive to apoptosis. J Cell Physiol 200: 223-234, 2004.

12. Budworth $\mathrm{J}$ and Gescher A: Differential inhibition of cytosolic and membrane-derived protein kinase $\mathrm{C}$ activity by staurosporine and other kinase inhibitors. FEBS Lett 362: 139-142, 1995.

13. Kruman I, Guo Q and Mattson MP: Calcium and reactive oxygen species mediate staurosporine-induced mitochondrial dysfunction and apoptosis in PC12 cells. J Neurosci Res 51: 293-308, 1998.

14. Panaretakis T, Laane E, Pokrovskaja K, Bjorklund AC, Moustakas A, Zhivotovsky B, Heyman M, Shoshan MC and Grander D: Doxorubicin requires the sequential activation of caspase-2, protein kinase $\mathrm{C}$ delta, and c-Jun NH2-terminal kinase to induce apoptosis. Mol Biol Cell 16: 3821-3831, 2005.

15. Lasfer M, Davenne L, Vadrot N, Alexia C, Sadji-Ouatas Z, Bringuier AF, Feldmann G, Pessayre D and Reyl-Desmars F: Protein kinase PKC delta and c-Abl are required for mitochondrial apoptosis induction by genotoxic stress in the absence of p53, p73 and Fas receptor. FEBS Lett 580: 2547-2552, 2006.

16. Hajnoczky G, Davies E and Madesh M: Calcium signaling and apoptosis. Biochem Biophys Res Commun 304: 445-454, 2003.

17. Rizzuto R, Pinton P, Ferrari D, Chami M, Szabadkai G, Magalhaes PJ, Di Virgilio F and Pozzan T: Calcium and apoptosis: facts and hypotheses. Oncogene 22: 8619-8627, 2003.

18. Stout AK, Raphael HM, Kanterewicz BI, Klann E and Reynolds IJ: Glutamate-induced neuron death requires mitochondrial calcium uptake. Nat Neurosci 1: 366-373, 1998.

19. Almeida A, Heales SJ, Bolanos JP and Medina JM: Glutamate neurotoxicity is associated with nitric oxide-mediated mitochondrial dysfunction and glutathione depletion. Brain Res 790: 209-216, 1998

20. Gonzalez-Zulueta M, Ensz LM, Mukhina G, Lebovitz RM, Zwacka RM, Engelhardt JF, Oberley LW, Dawson VL and Dawson TM: Manganese superoxide dismutase protects nNOS neurons from NMDA and nitric oxide-mediated neurotoxicity. J Neurosci 18: 2040-2055, 1998.

21. Ghafourifar P and Richter C: Nitric oxide synthase activity in mitochondria. FEBS Lett 418: 291-296, 1997

22. Ghafourifar P and Cadenas E: Mitochondrial nitric oxide synthase. Trends Pharmacol Sci 26: 190-195, 2005. 
23. Ghafourifar P, Schenk U, Klein SD and Richter C: Mitochondrial nitric-oxide synthase stimulation causes cytochrome c release from isolated mitochondria. Evidence for intramitochondrial peroxynitrite formation. J Biol Chem 274: 31185-31188, 1999.

24. Zenebe WJ, Nazarewicz RR, Parihar MS and Ghafourifar P: Hypoxia/Reoxygenation of isolated rat heart mitochondria causes cytochrome c release and oxidative stress; evidence for involvement of mitochondrial nitric oxide synthase. J Mol Cell Cardiol 43: 411-419, 2007.

25. Sun XM, Snowden RT, Skilleter DN, Dinsdale D, Ormerod MG and Cohen GM: A flow-cytometric method for the separation and quantitation of normal and apoptotic thymocytes. Anal Biochem 204: 351-356, 1992.

26. Trollinger DR, Cascio WE and Lemasters JJ: Mitochondrial calcium transients in adult rabbit cardiac myocytes: inhibition by ruthenium red and artifacts caused by lysosomal loading of $\mathrm{Ca}(2+)$-indicating fluorophores. Biophys J 79: 39-50, 2000.

27. Hajnoczky G, Hager R and Thomas AP: Mitochondria suppress local feedback activation of inositol 1,4,5-trisphosphate receptors by $\mathrm{Ca}^{2+}$. J Biol Chem 274: 14157-14162, 1999.

28. Dedkova EN, Ji X, Lipsius SL and Blatter LA: Mitochondrial calcium uptake stimulates nitric oxide production in mitochondria of bovine vascular endothelial cells. Am J Physiol Cell Physiol 286: C406-C415, 2004.

29. Nicholls DG: Simultaneous monitoring of ionophore- and inhibitor-mediated plasma and mitochondrial membrane potential changes in cultured neurons. J Biol Chem 281: 14864-14874, 2006.

30. Kristian T and Siesjo BK: Calcium in ischemic cell death. Stroke 29: 705-718, 1998.

31. Starkov AA, Chinopoulos C and Fiskum G: Mitochondrial calcium and oxidative stress as mediators of ischemic brain injury. Cell Calcium 36: 257-264, 2004.

32. Halestrap AP: Calcium, mitochondria and reperfusion injury: a pore way to die. Biochem Soc Trans 34: 232-237, 2006.

33. Susin SA, Lorenzo HK, Zamzami N, Marzo I, Snow BE, Brothers GM, Mangion J, Jacotot E, Costantini P, Loeffler M, Larochette N, Goodlett DR, Aebersold R, Siderovski DP, Penninger JM and Kroemer G: Molecular characterization of mitochondrial apoptosis-inducing factor. Nature 397: 441-446, 1999.

34. Miyata H, Silverman HS, Sollott SJ, Lakatta EG, Stern MD and Hansford RG: Measurement of mitochondrial free $\mathrm{Ca}^{2+}$ concentration in living single rat cardiac myocytes. Am J Physiol 261: H1123-H1134, 1991.

35. Coll KE, Joseph SK, Corkey BE and Williamson JR: Determination of the matrix free $\mathrm{Ca}^{2+}$ concentration and kinetics of $\mathrm{Ca}^{2+}$ efflux in liver and heart mitochondria. J Biol Chem 257: 8696-8704, 1982.

36. Tyler DD: Metabolite transporting systems of mitochondria. In: The Mitochondrion in Health and Disease. VCH Publisher, New York, NY, pp403-441, 1992.

37. Baek JH, Lee YS, Kang CM, Kim JA, Kwon KS, Son HC and $\mathrm{Kim} \mathrm{KW}$ : Intracellular $\mathrm{Ca}^{2+}$ release mediates ursolic acidinduced apoptosis in human leukemic HL-60 cells. Int J Cancer 73: 725-728, 1997.

38. McConkey DJ and Orrenius S: The role of calcium in the regulation of apoptosis. Biochem Biophys Res Commun 239: 357-366, 1997.

39. Ashraf M, Sybers HD and Bloor CM: X-ray microanalysis of ischemic myocardium. Exp Mol Pathol 24: 435-440, 1976.
40. Karcsu S, Laszlo FA, Toth L, Jancso G and Bacsy E: Calciumcontaining mitochondrial granules in neurohypophysial axon terminals disappear following vasopressin treatment of Brattleboro rats. Neurosci Lett 39: 181-185, 1983.

41. Pozzan T, Rizzuto R, Volpe P and Meldolesi J: Molecular and cellular physiology of intracellular calcium stores. Physiol Rev 74: 595-636, 1994.

42. Pozzan T, Magalhaes $\mathrm{P}$ and Rizzuto R: The comeback of mitochondria to calcium signalling. Cell Calcium 28: 279-283, 2000 .

43. Chang YJ and Chang KJ: Calcium concentration in rat liver mitochondria during anoxic incubation. J Formos Med Assoc 101: 136-143, 2002.

44. Rousou AJ, Ericsson M, Federman M, Levitsky S and McCully JD: Opening of mitochondrial KATP channels enhances cardioprotection through the modulation of mitochondrial matrix volume, calcium accumulation, and respiration. Am J Physiol Heart Circ Physiol 287: H1967-H1976, 2004.

45. Kanai AJ, Pearce LL, Clemens PR, Birder LA, VanBibber MM, Choi SY, de Groat WC and Peterson J: Identification of a neuronal nitric oxide synthase in isolated cardiac mitochondria using electrochemical detection. Proc Natl Acad Sci USA 98: 14126-14131, 2001.

46. Clementi E, Brown GC, Foxwell N and Moncada S: On the mechanism by which vascular endothelial cells regulate their oxygen consumption. Proc Natl Acad Sci USA 96: 1559-1562, 1999.

47. Borutaite V, Matthias A, Harris H, Moncada S and Brown GC: Reversible inhibition of cellular respiration by nitric oxide in vascular inflammation. Am J Physiol Heart Circ Physiol 281: H2256-H2260, 2001.

48. Kroemer G and Reed JC: Mitochondrial control of cell death. Nat Med 6: 513-519, 2000.

49. Teiten MH, Marchal S, D'Hallewin MA, Guillemin F and Bezdetnaya L: Primary photodamage sites and mitochondrial events after Foscan photosensitization of MCF-7 human breast cancer cells. Photochem Photobiol 78: 9-14, 2003.

50. Kallio A, Zhang A, Dahllund J, Heiskanen KM and Harkonen P: Role of mitochondria in tamoxifen-induced rapid death of MCF-7 breast cancer cells. Apoptosis 10: 1395-1410, 2005.

51. Cui S, Reichner JS, Mateo RB and Albina JE: Activated murine macrophages induce apoptosis in tumor cells through nitric oxide-dependent or -independent mechanisms. Cancer Res 54: 2462-2467, 1994.

52. Barreiro E, Comtois AS, Gea J, Laubach VE and Hussain SN: Protein tyrosine nitration in the ventilatory muscles: role of nitric oxide synthases. Am J Respir Cell Mol Biol 26: 438-446, 2002.

53. Wilson MR: Apoptosis: unmasking the executioner. Cell Death Differ 5: 646-652, 1998.

54. Bossy-Wetzel E, Newmeyer DD and Green DR: Mitochondrial cytochrome c release in apoptosis occurs upstream of DEVDspecific caspase activation and independently of mitochondrial transmembrane depolarization. EMBO J 17: 37-49, 1998.

55. Cardone MH, Roy N, Stennicke HR, Salvesen GS, Franke TF, Stanbridge E, Frisch S and Reed JC: Regulation of cell death protease caspase-9 by phosphorylation. Science 282: 1318-1321, 1998.

56. Hortelano S, Alvarez AM and Bosca L: Nitric oxide induces tyrosine nitration and release of cytochrome c preceding an increase of mitochondrial transmembrane potential in macrophages. FASEB J 13: 2311-2317, 1999. 